\title{
SIMULASI PEREDAMAN DISTORSI HARMONISA MENGGUNAKAN FILTER AKTIF DAN ANALISIS RUGI- RUGI DAYA PADA SISTEM KELISTRIKAN DI HOTEL THE BENE KUTA
}

\author{
I Nyoman Agus Sudiatma Pratama ${ }^{1}$, I Wayan Rinas ${ }^{2}$, Antonius Ibi Weking ${ }^{3}$ \\ Program Studi Teknik Elektro, Fakultas Teknik, Universitas Udayana Denpasar - Bali \\ Email :agus.sudiatma@gmail.com ${ }^{1}$, rinas@unud.ac.id $^{2}$, tony@ee.unud.ac.id $^{3}$
}

\begin{abstract}
ABSTRAK
Pengoperasian beban non linier pada sistem tenaga listrik akan menimbulkan harmonisa. Pengoperasian beban non linier pada simulasi sistem kelistrikan di hotel The Bene Kuta menimbulkan arus harmonisa yang mengakibatkan rugi-rugi daya. Simulasi menggunakan software ETAP, dan menentukan standar THD (Total Harmonic Distortion) menurut IEEE 519-

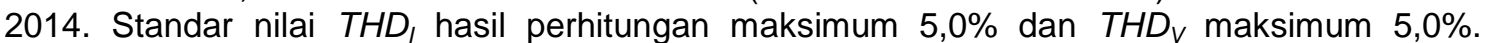
Membandingkan hasil simulasi dengan standar yang ditentukan, pemasangan filter aktif high pass, serta analisis rugi-rugi daya sebelum dan sesudah pemasangan filter. Nilai $T H D$, hasil simulasi masih belum memenuhi standar dengan rata-rata adalah 9,7\%. Adanya pemasangan filter aktif high pass dapat mereduksi distorsi harmonisa dengan nilai $T H D$, rata-rata $1,5 \%$ dan nilai rata-rata $T H D_{V}$ sebesar $0,31 \%$. Total rugi-rugi daya sebelum pemasangan filter aktif adalah 153.119,8 Watt dan sesudah pemasangan filter menjadi 1.511,2 Watt. Penurunan nilai filter yang digunakan $70 \%$ dari kemampuan maksimal filter guna mendapatkan filter yang lebih efisien, tetapi masih memenuhi standar THD yang ditentukan. Total rugi-rugi daya sistem kelistrikan diperoleh $11.885,5 \mathrm{~W}$.
\end{abstract}

Kata Kunci : Beban non-linier, Harmonisa, Filter Aktif, Rugi- rugi daya.

\section{ABSTRACT}

A non-linear load operation on a power system will generate harmonics. Operating nonlinear loads on the simulated electrical system at the Bene Hotel Kuta created a harmonic current which resulted in power losses. In this study, the simulation used ETAP software, and determined the standard of THD (Total Harmonic Distortion) according to IEEE 519-2014, the standard maximum $T H D_{1}$, value $5.0 \%$ and $T H D_{V}$ maximum 5,0\%. Compared the simulation results with the specified standards, installation of a high pass active filter, as well as power loss analysis before and after filter installation. $T H D$, value of simulation result did not still meet the standard, with the average being $9.7 \%$. The installation of a high pass active filter could reduce

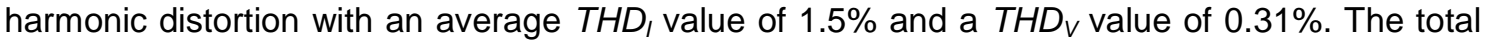
power loss prior to installation of active filter was 153,119.8 Watt and after the installation it became 1,511.2 Watt. The decrease in filter values used $70 \%$ of the filter's maximum capability to obtain a more efficient filter, but it still met the specified THD standard. Total loss of power on electrical system was $11,885.5 \mathrm{~W}$.

Keywords: Non-linear loads, Harmonics, Active Filter, Power losses.

1. PENDAHULUAN

I Nyoman Agus Sudiatma Pratama, I Wayan Rinas, Antonius Ibi Weking
Pengoprasian beban non linier di dalam suatu sistem kelistrikan terus meningkat 
dengan mempertimbangkan efisiensi daya. Disisi lain, beban non linier menyebabkan mutu daya listrik semakin rendah salah satunya adalah gejala harmonisa.

Harmonisa dapat mengakibatkan mutu daya menurun serta terjadinya rugi-rugi daya. Harmonisa ini dapat diminimalisir dengan pemasangan filter harmonisa. Tujuan pemasangan filter harmonisa untuk mereduksi amplitudo frekuensi dari sebuah tegangan atau arus.

Sistem kelistrikan Hotel The Bene Kuta disuplai dari PLN dengan kapasitas 630 kVA. Hasil pengukuran di lapangan diperoleh besarnya $T H D_{\text {, }}$ pada MDP (Main Distribution Pannel) yaitu $10,58 \%$ yang melebihi standar yang ditentukan menurut IEEE 519-2014 yaitu tidak lebih dari 5\%. Kemudian untuk $T H D_{V}$ pada MDP yaitu $1,53 \%$ yang masih memenuhi standar yaitu di bawah $5 \%$.

Nilai harmonisa hasil pengukuran yang tinggi mengakibatkan kualitas daya listrik menurun. Dengan demikian perlu dilakukan pemasangan filter aktif untuk menangani distorsi harmonisa agar nantinya dapat memenuhi standar yang telah ditetapkan.

\section{KAJIAN PUSTAKA}

\subsection{Distorsi Harmonisa}

Distorsi Harmonisa merupakan cacat gelombang yang terjadi secara periodik yang terjadi pada gelombang tegangan, arus, atau daya yang diakibatkan pengoprasian beban non linier. Gelombang ini kemudian menumpang pada gelombang murni atau fundamental sehingga terbentuk gelombang cacat yang merupakan jumlah antara gelombang murni sesaat dengan gelombang harmonisanya [1].

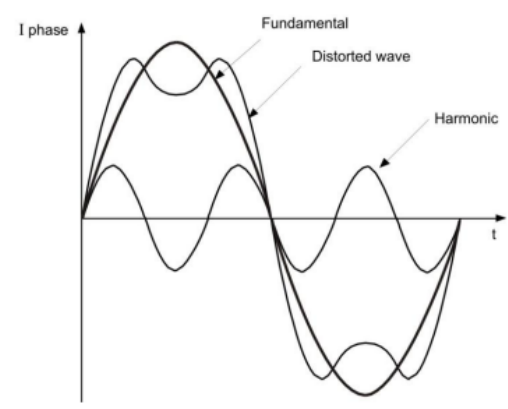

\section{Gambar 1. Bentuk Gelombang Terdistorsi.[2]}

Standar distorsi harmonisa yang baik untuk arus dan tegangan berdasarkan IEEE 519-2014 sesuai dengan Tabel 1 dan Tabel 2.

Tabel 1. Batas Distorsi Harmonik Arus untuk Sistem Distribusi Umum [3]

\begin{tabular}{|c|c|c|c|c|c|c|}
\hline \multicolumn{7}{|c|}{ Distorsi Harmonik Maksimum Arus dalam Persen } \\
dari $\mathbf{L}_{\mathbf{L}}$ \\
\hline \multirow{2}{*}{$\boldsymbol{I}_{\mathbf{s}} \boldsymbol{I}_{\mathbf{L}}$} & $\mathbf{3} \leq$ & $\mathbf{1 1} \leq$ & $\mathbf{1 7} \leq$ & $\mathbf{2 3} \leq$ & $\mathbf{3 5} \leq$ & \\
& $\mathbf{h}<$ & $\mathbf{h}<$ & $\mathbf{h}<$ & $\mathbf{h}<$ & $\mathbf{h}<$ & THD \\
& $\mathbf{1 1}$ & $\mathbf{1 7}$ & $\mathbf{2 3}$ & $\mathbf{3 5}$ & $\mathbf{5 0}$ & \\
\hline$<20^{*}$ & 4,0 & 2,0 & 1,5 & 0,6 & 0,3 & 5,0 \\
$20<50$ & 7,0 & 3,5 & 2,5 & 1,0 & 0,5 & 8,0 \\
$50<100$ & 10,0 & 4,5 & 4,0 & 1,5 & 0,7 & 12,0 \\
$100<1000$ & 12,0 & 5,5 & 5,0 & 2,0 & 1,0 & 15,0 \\
$>1000$ & 15,0 & 7,0 & 6,0 & 2,5 & 1,4 & 20,0 \\
\hline
\end{tabular}

Rasio hubung singkat ( $\mathrm{SC}_{\text {ratio }}$ ) dapat dicari dengan menggunakan rumus berikut.

$$
S C_{\text {ratio }}=\frac{I_{S C}}{I_{L}}
$$

Arus hubung singkat $\left(I_{s c}\right)$ dapat dihitung dengan persamaan berikut.

$$
I_{S C}=\frac{K V A \times 100}{\sqrt{3} \times K V \times Z(\%)}
$$

Arus beban maksimum $\left(I_{L}\right)$ dapat dihitung dengan persamaan berikut.

$$
I_{L}=\frac{K W}{P F \cdot \sqrt{3} \cdot K V}
$$

Tabel 2. Batas Maksimum Distorsi Tegangan [3]

\begin{tabular}{|c|c|c|}
\hline $\begin{array}{c}\text { Tegangan } \\
\text { Saluran pada } \\
\text { PCC }\end{array}$ & $\begin{array}{c}\text { Distorsi } \\
\text { Tegangan } \\
\text { Individu } \\
\mathbf{( \% )}\end{array}$ & $\begin{array}{c}\text { Jumlah } \\
\text { Distorsi } \\
\text { Tegangan } \\
\text { THD (\%) }\end{array}$ \\
\hline $\mathrm{V} \leq 1 \mathrm{kV}$ & 5,0 & 8,0 \\
\hline $\begin{array}{c}1 \mathrm{kV} \mathrm{sampai} \\
69 \mathrm{kV}\end{array}$ & 3,0 & 5,0 \\
\hline $\begin{array}{c}69 \mathrm{kV} \mathrm{sampai} \\
161 \mathrm{kV}\end{array}$ & 1,5 & 2,5 \\
\hline $\begin{array}{c}161 \mathrm{kV} \text { dan di } \\
\text { atasnya }\end{array}$ & 1,0 & 1,5 \\
\hline
\end{tabular}




\subsection{Filter Harmonisa}

Filter Aktif adalah suatu perangkat elektronik yang dapat memperbaiki kualitas daya yang dikirimkan dari sumber ke beban. Filter sistem tenaga listrik biasanya terdiri dari Filter Aktif dan Filter Pasif. Pemakaian Filter Aktif pada sistem tenaga listrik lebih fleksibel daripada Filter Pasif karena dari segi penggunaan dan unjuk kerja (performance) Filter Aktif lebih ekonomis [4].

Rangkaian dasar dari sebuah filter aktif high pass (Active High Pass Filter, HPF) adalah sebagai berikut.

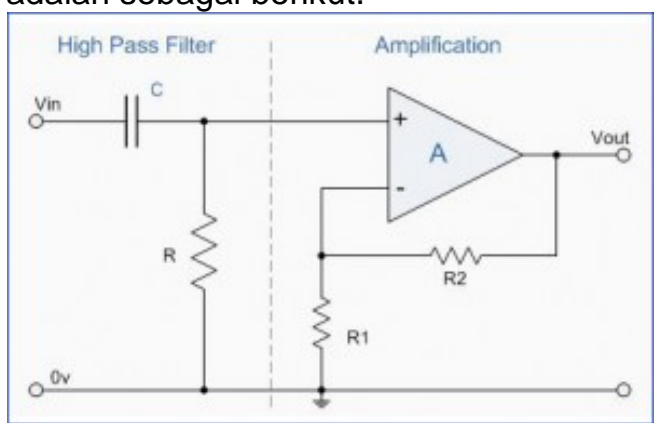

Gambar 2. Rangkaian Filter Aktif High Pass [4]

Daya reaktif untuk memperbaiki faktor daya :

$$
\begin{aligned}
& \theta_{1}=\operatorname{Arc} \cos \varphi_{\text {system }} \\
& \theta_{2}=\operatorname{Arc} \cos \varphi_{\text {normal }} \\
& \theta_{C}=P\left(\tan \theta_{1}-\tan \theta_{2}\right)
\end{aligned}
$$

Perhitungan nilai kapasitor :

$$
\begin{aligned}
& Q_{C}=\frac{V^{2}}{X_{C}} \\
& X_{C}=\frac{V^{2}}{k V a r} \\
& C=\frac{1}{2 \pi f X C}
\end{aligned}
$$

Perhitungan nilai Induktor :

$$
\begin{aligned}
& L=\frac{1}{(c)(2 \pi f n)^{2}} \\
& X_{L}=2 \pi f L
\end{aligned}
$$

\subsection{Rugi-Rugi Daya}

Rugi-rugi daya merupakan daya yang hilang dalam penyaluran daya listrik dari sumber daya utama ke suatu beban listrik. Dalam setiap penyaluran daya listrik ke beban pasti terdapat rugi-rugi daya yang diakibatkan oleh faktor tertentu seperti jarak saluran listrik ke beban terlalu jauh, yang mengakibatkan bertambah besar tahanan suatu saluran kabel yang digunakan.

$$
\mathrm{R}=\mathrm{p} \times \frac{\mathrm{L}}{\alpha}
$$

Pada keadaan beban seimbang, rugirugi daya yang terjadi pada saluran dapat dihitung menggunakan persamaan berikut [5]:

$$
P_{L}=3 \times I^{2} R_{\text {line }}
$$

\section{METODE PENELITIAN}

Penelitian dilakukan di Hotel The Bene Kuta yang beralamat di Jalan Benesari Kuta Bali. Jenis data yang digunakan adalah data primer yaitu data pengukuran langsung di pelanggan. Data tersebut meliputi data beban non linier, data transformator, single line diagram, data pengukuran THD arus dan THD tegangan, panjang penghantar. Data sekunder yang diperoleh dari sumber data kepustakaan (library research) yang berasal dari buku-buku yang berhubungan dengan penelitian. Tahapan analisis dapat dilihat sebagai berikut:

a. Pengambilan data berupa pengukuran THD arus dan tegangan serta pembagian beban pada setiap SPD di hotel The Bene Kuta

b. Menghitung arus hubung singkat ( $\left.I_{s c}\right)$, menghitung kapasitas daya aktif setiap SDP, hitung arus beban maksimum $\left(I_{L}\right)$

c. Menghitung $S C_{\text {ratio }}$ serta menentukan batas maksimum $T H D_{\text {, dan }} T H D_{V}$ yang digunakan berdasarkan standar IEEE 519-2014.

d. Pemodelan sistem kelistrikan The Bene Hotel dan analisis simulasi $T H D_{\text {, dan }}$ $T H D_{V}$ dengan menggunakan software ETAP.

e. Jika simulasi tidak menunjukan adanya THD berlebih maka tidak diperlukan pemasangan filter harmonisa. Jika menunjukan THD berlebih maka akan dipasang filter aktif. 
f. Desain dan pemasangan filter aktif pada simulasi untuk meredam distorsi harmonisa.

g. Membandingkan hasil simulasi $T H D_{\text {, }}$ dan $T H D_{V}$ setelah menggunakan filter aktif dengan standar IEEE 519 - 2014.

h. Menurunkan kapasitas filter harmonisa untuk mendapatkan nilai filter yang efisien.

i. Analisa $T H D_{\text {, dan }} T H D_{V}$ setelah pemasangan filter harmonisa serta menganalisa rugi-rugi daya.

j. Menarik kesimpulan.

\section{HASIL DAN PEMBAHASAN}

Pembahasan serta hasil meliputi simulasi sistem kelistrikan di Hotel The Bene Kuta, perhitungan spesifikasi filter aktif, serta menghitung rugi-rugi daya.

\subsection{Simulasi Kelistrikan Hotel The Bene Kuta}

Gambar 3 merupakan simulasi pemasangan filter aktif high pass pada sistem kelistrikan di Hotel The Bene Kuta pada software ETAP 7.0. Pemasangan filter dilakukan pada setiap SDP guna mendapatkan hasil THD yang maksimal serta memenuhi standard.

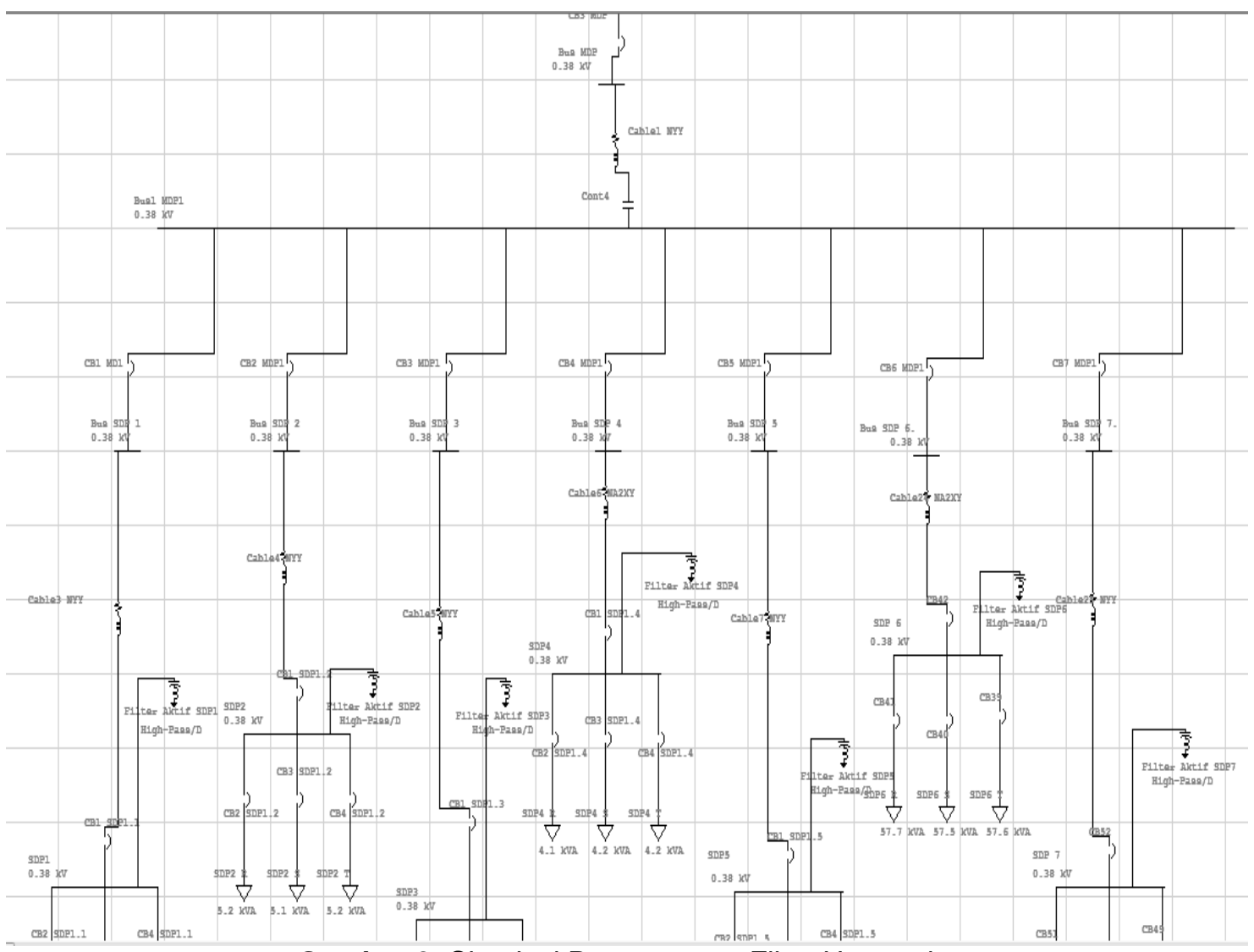

Gambar 3. Simulasi Pemasangan Filter Harmonisa

Tabel 3.Total Daya Beban Non Linier

\begin{tabular}{|l|c|c|}
\hline \multicolumn{2}{|c|}{ Tempat } & Total Daya KW \\
\hline \multirow{3}{*}{ MDP } & SDP 1 & 338.574 \\
\cline { 2 - 3 } & SDP 2 & 13.196 \\
\cline { 2 - 3 } & SDP 3 & 8.404 \\
\cline { 2 - 3 } & SDP 4 & 10.640 \\
\hline
\end{tabular}

\begin{tabular}{|c|c|c|}
\hline \multirow{2}{*}{ Total } & SDP 5 & 26.410 \\
\cline { 2 - 3 } & SDP 6 & 146.880 \\
\cline { 2 - 3 } & SDP 7 & 10.600 \\
\hline \multicolumn{2}{|c|}{ Total } & 554.704 \\
\hline
\end{tabular}


Total keseluruhan daya aktif pada sistem kelistrikan di hotel The Bene Kuta dari SDP 1 sampai SDP 7 adalah 554.704 $K W$.

\subsection{Spesifikasi Filter dan Hasil Analisa}

\subsubsection{Daya Reaktif}

Daya reaktif untuk memperbaiki faktor daya dapat dihitung seperti berikut :

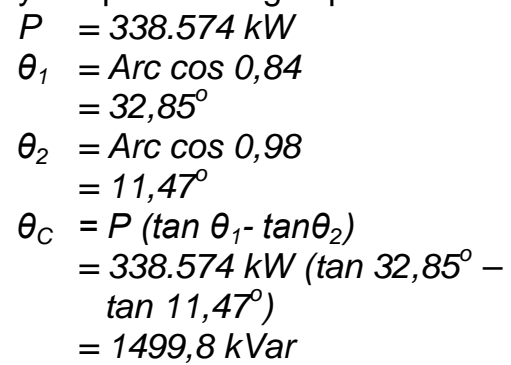

\subsubsection{Perhitungan Kapasitor} ini:

Perhitungan Kapasitor seperti dibawah

$$
\begin{aligned}
Q_{C} & =\frac{V^{2}}{X_{C}} \\
X_{C} & =\frac{V^{2}}{k V a r} \\
& =\frac{0.38 \mathrm{kV}^{2}}{1499,8 \mathrm{kVar}}=0,096 \Omega \\
& =\frac{1}{2 \pi f X c}, \mathrm{f}=\text { frekuensi fundamental } 50 \\
C & =\frac{1}{2 \pi f X c} \quad \mathrm{~Hz} \\
& =\frac{1}{(2)(3,14)(50 \mathrm{~Hz})(0.096 \Omega)}=2,764 \times 10^{-2} \mathrm{~F}
\end{aligned}
$$

\subsubsection{Perhitungan Induktor}

Dalam simulasi ini orde yang akan di filter adalah orde ke-5, sehingga pengaturan diturunkan sedikit dibawahnya yaitu 4,9. Ini dilakukan sebagai toleransi komponen filter untuk mencegah adanya resonansi yang bisa terjadi dalam sistem pada frekuensi yang mengganggu, serta guna mendapat-kan performa filter yang maksimal.

$$
\begin{aligned}
L & =\frac{1}{(C)(2 \pi f n)^{2}} \\
L & =\frac{1}{\left(2,764 \times 10^{-2}\right)(2 \times 3,14 \times 50 \times 4,9)^{2}} \\
& =0,0000106 \mathrm{H}
\end{aligned}
$$

$$
\begin{aligned}
X_{L} & =2 \pi f L \\
X_{L} & =2 \pi f L \\
& =(2)(3,14)(60)(0,0000106) \\
& =0,0039 \Omega
\end{aligned}
$$

\subsubsection{Perhitungan Resistor}

Pada perancangan filter aktif type highpass ini nilai $Q$ yang digunakan adalah 20 karena distorsi harmonisa yang besar terdapat pada orde 20 ke bawah. Nilai faktor kualitas (Q) ini merupakan ukuran ketajaman pengaturan filter untuk mereduksi harmonisa.

$$
\begin{aligned}
Q & =\frac{R}{X_{L}} \\
R & =Q \cdot X_{L} \\
& =(20)(0,0039) \\
& =0,078 \Omega
\end{aligned}
$$

Spesifikasi nilai kapasitor, induktor dan resistor filter aktif dari masing-masing SDP dapat dilihat pada Tabel 4 berikut ini.

Tabel 4. Spesifikasi Filter Aktif

\begin{tabular}{|c|c|c|c|}
\hline Filter & $\begin{array}{c}\text { Kapasitor } \\
(\mathbf{k V a r})\end{array}$ & $\begin{array}{c}\text { Induktor } \\
\left(\mathbf{X}_{\mathbf{L}}\right)\end{array}$ & $\begin{array}{c}\text { Resistor } \\
(\mathbf{R})\end{array}$ \\
\hline SDP 1 & $1.499,8$ & 0,0039 & 0,078 \\
\hline SDP 2 & 58,45 & 2,47 & 2 \\
\hline SDP 3 & 37,22 & 3,87 & 3,2 \\
\hline SDP 4 & 47,13 & 0,127 & 2,54 \\
\hline SDP 5 & 117 & 1,23 & 1 \\
\hline SDP 6 & 651 & 0,0092 & 0,18 \\
\hline SDP 7 & 46,95 & 3,07 & 2,5 \\
\hline
\end{tabular}

Hasil spektrum gelombang tegangan dari MDP dan SDP1 setelah pemasangan filter aktif sebagai berikut. Adanya pemasangan filter aktif dapat mengatasi distorsi harmonisa.
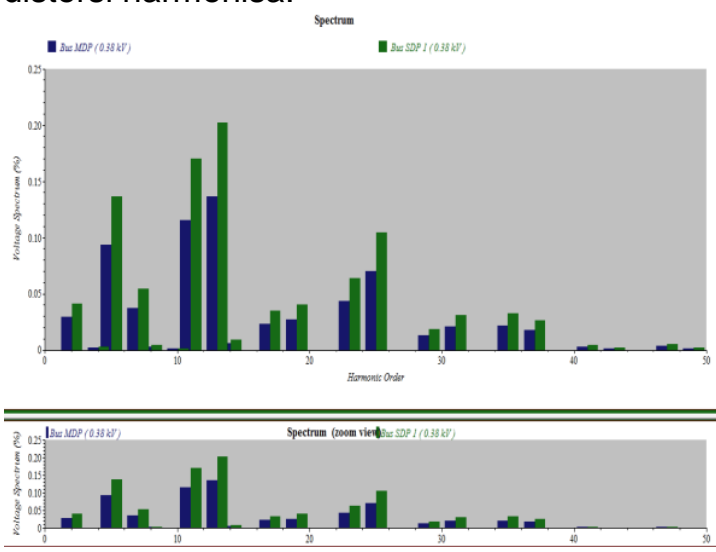
Gambar 5. Running Spektrum Setelah Pemasangan Filter Aktif
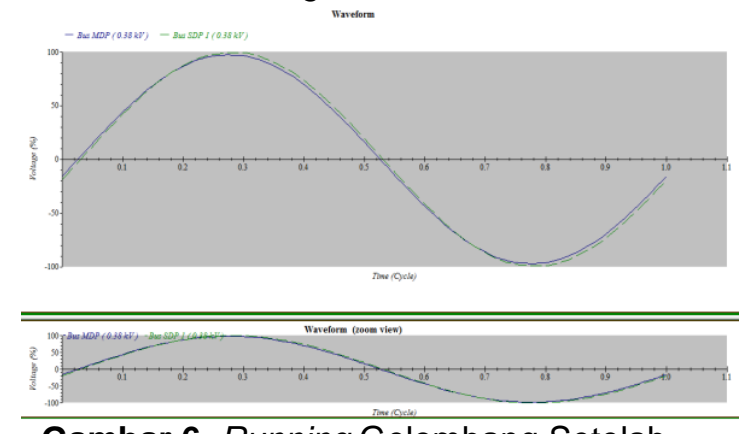

Gambar 6. Running Gelombang Setelah

Pemasangan Filter Aktif

Perbandingan hasil running spektrum dan gelombang tegangan dari MDP dan SDP1 setelah pemasangan filter aktif. Dengan adanya pemasangan filter aktif harmonisa dapat mengatasi cacat gelombang akibat distorsi harmonisa dan gelombang akan terlihat lebih sempurna.

Berdasarkan hasil perhitungan shortcircuit rasio sesuai dengan standar IEEE 519-2014, berikut perbandingan hasil pengoperasian simulasi setelah pemasangan filter aktif.

Tabel 5. Kandungan $T H D$, Setelah Pemasangan Filter Aktif

\begin{tabular}{|c|c|c|c|c|c|}
\hline \multicolumn{2}{|c}{} & \multicolumn{2}{|c|}{ Hasil Running Kandungan THD } & \multirow{2}{*}{ Keteran- } \\
\cline { 2 - 5 } Tempat & $\begin{array}{c}\text { Sebelum } \\
\text { pemasa- } \\
\text { ngan } \\
\text { filter }\end{array}$ & $\begin{array}{c}\text { Sesudah } \\
\text { pemasa- } \\
\text { ngan } \\
\text { filter } \\
\text { aktif }\end{array}$ & $\begin{array}{c}\text { IEEE } \\
519- \\
2014\end{array}$ & \\
\hline & $\begin{array}{c}\text { SDP } \\
1\end{array}$ & $16,04 \%$ & $0,81 \%$ & $5 \%$ & $\begin{array}{c}\text { Meme- } \\
\text { nuhi } \\
\text { Standar }\end{array}$ \\
\cline { 2 - 5 } & $\begin{array}{c}\text { SDP } \\
2\end{array}$ & $8,84 \%$ & $1,97 \%$ & $5 \%$ & $\begin{array}{c}\text { Meme- } \\
\text { nuhi } \\
\text { Standar }\end{array}$ \\
\cline { 2 - 5 } & $\begin{array}{c}\text { SDP } \\
3\end{array}$ & $8,76 \%$ & $1,92 \%$ & $5 \%$ & $\begin{array}{c}\text { Meme- } \\
\text { nuhi } \\
\text { Standar }\end{array}$ \\
\cline { 2 - 5 } MDP & $\begin{array}{c}\text { SDP } \\
4\end{array}$ & $7,30 \%$ & $0,86 \%$ & $5 \%$ & $\begin{array}{c}\text { Meme- } \\
\text { nuhi } \\
\text { Standar }\end{array}$ \\
\cline { 2 - 5 } & $\begin{array}{c}\text { SDP } \\
5\end{array}$ & $9,82 \%$ & $2,30 \%$ & $5 \%$ & $\begin{array}{c}\text { Meme- } \\
\text { nuhi } \\
\text { Standar }\end{array}$ \\
\hline $\begin{array}{c}\text { SDP } \\
6\end{array}$ & $10,57 \%$ & $1,05 \%$ & $5 \%$ & $\begin{array}{c}\text { Meme- } \\
\text { nuhi } \\
\text { Standar }\end{array}$ \\
\hline $\begin{array}{c}\text { SDP } \\
7\end{array}$ & $7,06 \%$ & $1,68 \%$ & $5 \%$ & $\begin{array}{c}\text { Meme- } \\
\text { nuhi }\end{array}$ \\
\hline
\end{tabular}

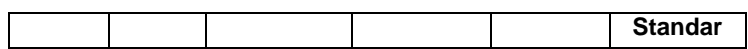

Pemasangan filter aktif akan dapat mereduksi distorsi harmonisa pada sistem kelistrikan dengan nilai $T H D$, pada SDP1 sebesar 0,68\%, SDP2 sebesar 1,94\%, SDP3 sebesar 1,89\%, SDP4 sebesar $0,86 \%$, SDP5 sebesar 2,29\%, SDP6 sebesar 0,81\%, dan SDP7 sebesar 1,67\%. Nilai tersebut telah memenuhi standar IEEE 519-2014. Kandungan $T H D$, pada sistem kelistrikan akan sangat berpengaruh terhadap kualitas daya listrik yang tentunya berpengaruh juga dengan rugi-rugi daya yang ditimbulkan. Dengan adanya penurunan $T H D_{l}$, rugi-rugi daya listrik secara langsung akan mengalami penurunan. Dari pihak Hotel juga akan mendapatkan keringanan pembayaran beban listrik dikarenakan rugi-rugi daya yang ditimbulkan dari proses pengoperasian alat-alat dapat diminimalisir.

Tabel 6. Kandungan $T H D_{V}$ Setelah Pemasangan Filter Aktif

\begin{tabular}{|c|c|c|c|c|c|}
\hline \multirow{2}{*}{\multicolumn{2}{|c|}{ Tempat }} & \multicolumn{3}{|c|}{ Hasil Running Kandungan THD } & \multirow{3}{*}{$\begin{array}{c}\text { Keteran- } \\
\text { gan } \\
\\
\text { Meme- } \\
\text { nuhi } \\
\text { Standar }\end{array}$} \\
\hline & & \multirow{2}{*}{$\begin{array}{c}\begin{array}{c}\text { Sebelum } \\
\text { pemasa- } \\
\text { ngan } \\
\text { filter }\end{array} \\
1,92 \%\end{array}$} & \multirow{2}{*}{$\begin{array}{c}\begin{array}{c}\text { Sesudah } \\
\text { pemasa- } \\
\text { ngan } \\
\text { filter } \\
\text { aktif }\end{array} \\
0,31 \%\end{array}$} & \multirow{2}{*}{$\begin{array}{c}\text { IEEE } \\
519- \\
2014 \\
5 \%\end{array}$} & \\
\hline \multirow{7}{*}{ MDP } & $\begin{array}{c}\text { SDP } \\
1\end{array}$ & & & & \\
\hline & $\begin{array}{c}\text { SDP } \\
2\end{array}$ & $1,92 \%$ & $0,31 \%$ & $5 \%$ & $\begin{array}{c}\text { Meme- } \\
\text { nuhi } \\
\text { Standar }\end{array}$ \\
\hline & $\begin{array}{c}\text { SDP } \\
\mathbf{3}\end{array}$ & $1,92 \%$ & $0,31 \%$ & $5 \%$ & $\begin{array}{c}\text { Meme- } \\
\text { nuhi } \\
\text { Standar }\end{array}$ \\
\hline & $\begin{array}{c}\text { SDP } \\
4\end{array}$ & $1,92 \%$ & $0,31 \%$ & $5 \%$ & $\begin{array}{l}\text { Meme- } \\
\text { nuhi } \\
\text { Standar }\end{array}$ \\
\hline & $\begin{array}{c}\text { SDP } \\
5\end{array}$ & $1,92 \%$ & $0,31 \%$ & $5 \%$ & $\begin{array}{c}\text { Meme- } \\
\text { nuhi } \\
\text { Standar }\end{array}$ \\
\hline & $\begin{array}{c}\text { SDP } \\
6\end{array}$ & $1,92 \%$ & $0,31 \%$ & $5 \%$ & $\begin{array}{c}\text { Meme- } \\
\text { nuhi } \\
\text { Standar }\end{array}$ \\
\hline & $\begin{array}{c}\text { SDP } \\
7\end{array}$ & $1,92 \%$ & $0,31 \%$ & $5 \%$ & $\begin{array}{c}\text { Meme- } \\
\text { nuhi } \\
\text { Standar }\end{array}$ \\
\hline
\end{tabular}

Nilai $T H D_{V}$ sistem kelistrikan hotel The Bene Kuta masih memenuhi standar IEEE 519-2014 yaitu dibawah 5\% dengan nilai hasil running simulasi untuk $T H D_{V}$ pada semua SDP sebelum pemasangan filter 
aktif yaitu 2,15\% dan sesudah pemasangan filter aktif yaitu 0,34\%. Dengan adanya penurunan $T H D_{\text {l }}$ maka $T H D_{V}$ akan ikut turun dan hasilnya akan lebih kecil yang menandakan semakin baiknya kualitas tegangan setelah pemasangan filter aktif.

Dari spesifikasi filter hasil perhitungan menurut rumus didapat nilai THD yang sangat baik namun dengan adanya pemasangan filter disetiap SDP tentu nantinya akan tidak efisien. Dengan demikian untuk pertimbangan efisiensi akan digunakan spesifikasi filter yang lebih kecil. Spesifikasi filter ini akan menghasilkan THD yang mendekati standar 5\% THD agar filter nantinya lebih efisien.

Nilai kapasitor filter hasil perhitungan menggunakan rumus pada SDP1 adalah

Tabel 7. Penurunan Spesifikasi Filter dan Perbandingan THD Guna Mendapatkan Filter yang Lebih Efisien

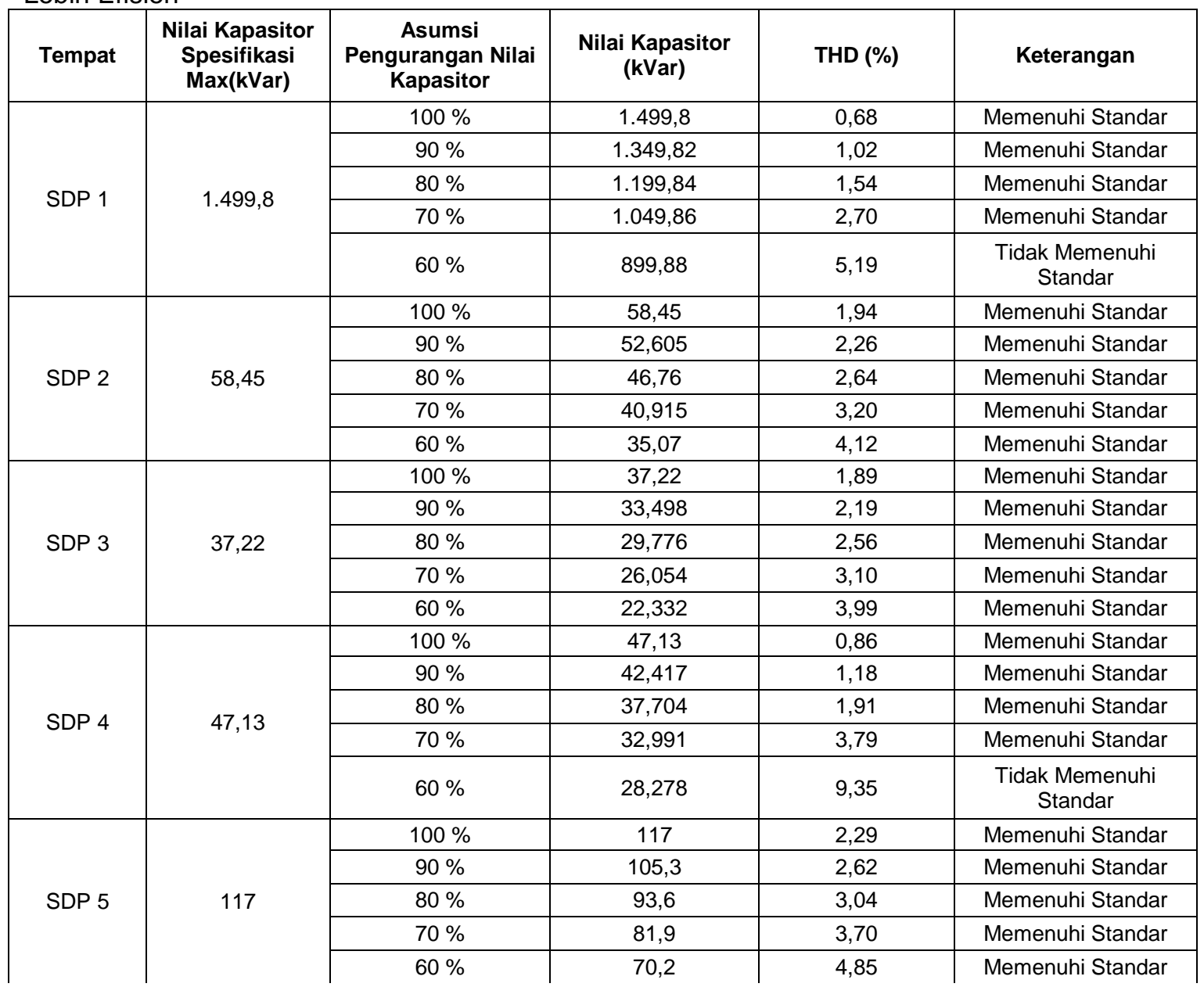

1.499,8 kVar $=100 \%$ (dianggap kemampuan maksimum filter dalam mereduksi harmonisa), akan dilakukan penurunan $90 \%, 80 \%, 70 \%, 60 \%$ dari nilai maksimum kemampuan filter agar filter dapat lebih efisien.

Asumsi pertama akan menggunakan 90\% dari kemampuan maksimum filter dapat dihitung sebagai berikut.

$$
C=\frac{90}{100} x 1499,8 \mathrm{kVar}=1349,82 \mathrm{kVar}
$$
spesifikasi kapasitor filter dengan asumsi 


\begin{tabular}{|c|c|c|c|c|c|}
\hline \multirow{3}{*}{ SDP 6 } & & $100 \%$ & 651 & 0,81 & Memenuhi Standar \\
\cline { 3 - 6 } & \multirow{4}{*}{651} & $90 \%$ & 585,9 & 1,31 & Memenuhi Standar \\
\cline { 3 - 6 } & & $80 \%$ & 520,8 & 1,83 & Memenuhi Standar \\
\cline { 3 - 6 } & & $70 \%$ & 455,7 & 2,94 & Memenuhi Standar \\
\cline { 3 - 6 } & & $60 \%$ & 390,6 & 5,41 & $\begin{array}{c}\text { Tidak Memenuhi } \\
\text { Standar }\end{array}$ \\
\hline \multirow{3}{*}{ SDP 7 } & \multirow{3}{*}{46,95} & $100 \%$ & 46,95 & 1,67 & Memenuhi Standar \\
\cline { 3 - 6 } & & $90 \%$ & 42,255 & 1,91 & Memenuhi Standar \\
\cline { 3 - 6 } & & $80 \%$ & 37,56 & 2,24 & Memenuhi Standar \\
\cline { 3 - 6 } & & $70 \%$ & 32,865 & 2,75 & Memenuhi Standar \\
\cline { 3 - 6 } & & $60 \%$ & 28,17 & 3,68 & Memenuhi Standar \\
\hline
\end{tabular}

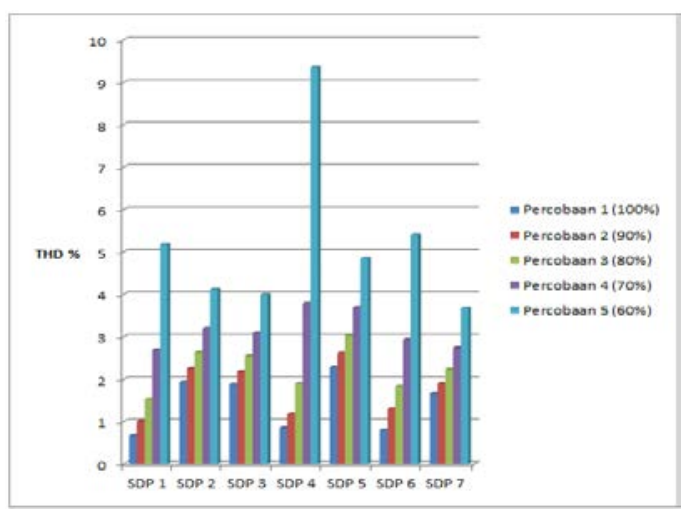

Gambar 7. Diagram Batang Hasil Percobaan Asumsi Nilai Kapasitor Terhadap THD

Hasil perhitungan nilai filter menggunakan persamaan digunakan sebagai acuan nilai maksimum kinerja filter.Tabel diatas dimaksudkan spesifikasi nilai filter dapat diturunkan guna mendapatkan filter yang lebih efisien.

\subsection{Analisis Rugi - Rugi}

Perhitungan analisis rugi-rugi daya pada SDP1 sebagai berikut.

\section{Diketahui :}

$$
\begin{aligned}
& \rho=1,68 \times 10^{-8} \Omega . \mathrm{m} \\
& l=12 \mathrm{~m} \\
& d=50 \mathrm{~mm} \rightarrow r=25 \mathrm{~mm}=25 \times 10^{-3} \mathrm{~m}
\end{aligned}
$$

Luas penampang ( $\alpha$ ) penghantar tersebut menggunakan rumus luas lingkaran, yaitu:

$$
\begin{aligned}
L & =\pi r^{2} \\
L & =\left(\frac{22}{7}\right) \times\left(25 \times 10^{-3} m\right)^{2}
\end{aligned}
$$

$$
L \quad=19,6 \times 10^{-4} \mathrm{~m}^{2}
$$

Besarnya hambatan dari penghantar pada SDP1 adalah sebagai berikut:

$$
\begin{aligned}
& R=p \times \frac{l}{\alpha} \\
& R=1,68 \times 10^{-8} \Omega . m \times \frac{12 m}{19,6 \times 10^{-4} m^{2}} \\
& R=0,0001 \Omega
\end{aligned}
$$

Diketahui nilai arus fundamental sistem untuk SDP1 pada simulasi adalah 1.806,7A dan THD 16,04\% maka :

$$
\begin{aligned}
I_{h} & =I_{\text {fun }} \times \text { THD } \\
I_{h} & =1806,7 \times 16,04 \% \\
& =289 \mathrm{~A}
\end{aligned}
$$

Dengan diketahui besar arus harmonisa, maka rugi - rugi pada SDP 1 sebelum pemasangan filter harmonisa sebagai berikut :

$$
\begin{aligned}
P_{L} & =3 \times I^{2} R_{\text {line }} \\
P_{L} & =\left(3 \times(289)^{2}\right) \times 0,0001 \\
& =25,06 \text { watt }
\end{aligned}
$$

Berdasarkan perhitungan tersebut maka dengan menggunakan persamaan yang sama hasil perhitungan dapat dilihat pada Tabel 8.

Tabel 8. Rugi-Rugi Daya Sebelum Pemasangan Filter Aktif

\begin{tabular}{|c|c|c|c|c|}
\hline \multicolumn{2}{|c|}{ Tempat } & $\mathbf{R}_{\text {line }}(\mathbf{\Omega})$ & $\mathbf{I}_{\mathbf{h}}(\mathbf{A})$ & $\begin{array}{c}\text { Rugi-Rugi } \\
\text { (watt) }\end{array}$ \\
\hline \multirow{4}{*}{ MDP } & SDP 1 & 0,0001 & 289 & 25,06 \\
\cline { 2 - 5 } & SDP 2 & 0,0002 & 8,35 & 0,04 \\
\cline { 2 - 5 } & SDP 3 & 0,003 & 5,33 & 0,25 \\
\cline { 2 - 5 } & SDP 4 & 9,7 & 4,23 & 525,6 \\
\cline { 2 - 5 } & SDP 5 & 0,001 & 18,38 & 1,01 \\
\cline { 2 - 5 } & SDP 6 & 7,4 & 82,9 & $152.567,5$ \\
\cline { 2 - 5 } & SDP 7 & 0,004 & 5,33 & 0,34 \\
\hline
\end{tabular}




\section{Total}

$153.119,8$

Tabel 9 merupakan perbandingan rugirugi daya sebelum dan sesudah pemasangan filter aktif high pass. Rugi- rugi daya menurun akibat pemasangan filter aktif. Penurunan rugi-rugi daya secara signifikan terjadi pada SDP 6 karena banyaknya pengoperasian beban non linier yang mengakibatkan rugi-rugi daya tinggi.

Tabel 9. Perbandingan Rugi-Rugi Daya Sebelum dan Sesudah Pemasangan Filter Aktif

\begin{tabular}{|c|c|c|c|}
\hline \multicolumn{2}{|c|}{ Tempat } & $\begin{array}{c}\text { Rugi-Rugi } \\
\text { Sebelum } \\
\text { Pemasangan } \\
\text { Filter (watt) }\end{array}$ & $\begin{array}{c}\text { Rugi-Rugi } \\
\text { Sesudah } \\
\text { Pemasangan } \\
\text { Filter (watt) }\end{array}$ \\
\hline \multirow{6}{*}{ MDP } & SDP 1 & 25,06 & 0,06 \\
\cline { 2 - 4 } & SDP 2 & 0,04 & 0,002 \\
\cline { 2 - 4 } & SDP 3 & 0,25 & 0,01 \\
\cline { 2 - 4 } & SDP 4 & 525,6 & 7,3 \\
\cline { 2 - 4 } & SDP 5 & 1,01 & 0,06 \\
\cline { 2 - 4 } & SDP 6 & $152.567,5$ & $1.503,7$ \\
\cline { 2 - 4 } & SDP 7 & 0,34 & 0,02 \\
\hline \multicolumn{2}{|c|}{ Total } & $\mathbf{1 5 3 . 1 1 9 , 8}$ & $\mathbf{1 . 5 1 1 , 2}$ \\
\hline
\end{tabular}

Pemasangan filter aktif high pass pada simulasi memberikan penurunan nilai rugirugi daya di dalam system kelistrikan. Pada Tabel 9 total rugi-rugi sebelum pemasangan $153.119,8 \mathrm{~W}$ dan setelah pemasangan filter menjadi 1.511,2 W.

Tabel 10. Perbandingan Total Rugi-Rugi Daya dengan Spesifikasi Filter yang Diturunkan

\begin{tabular}{|c|c|c|}
\hline \multirow{3}{*}{ Tempat } & $\begin{array}{c}\text { Spesifikasi } \\
\text { Filter }\end{array}$ & $\begin{array}{c}\text { Total Rugi- } \\
\text { Rugi Daya } \\
\text { (watt) }\end{array}$ \\
\hline \multirow{4}{*}{ MDP } & $100 \%$ & $1.511,2$ \\
\cline { 2 - 3 } & $90 \%$ & $2.369,7$ \\
\cline { 2 - 3 } & $80 \%$ & $4.575,1$ \\
\cline { 2 - 3 } & $70 \%$ & $11.885,5$ \\
\cline { 2 - 3 } & $60 \%$ & $40.761,9$ \\
\hline
\end{tabular}

Dengan adanya penurunan filter rugi rugi daya akan meningkat tetapi penurunan nilai filter ini masih memenuhi standar THD yang ditentukan. Penurunan nilai filter ini akan mengakibatkan harga pembuatan filter akan lebih murah.

\section{Simpulan}

Berdasarkan hasil simulasi dan analisis, maka didapatkan simpulan penyelesaian dari permasalahan yaitu :

Sistem kelistrikan pada Hotel The Bene Kuta disuplai oleh PLN dengan kapasitas daya $630 \mathrm{KVA}$. Total beban yang terpasang hasil pengukuran pada MDP adalah sebesar 190.672,5 watt.

Kandungan $T H D$, di Hotel The Bene Kuta hasil simulasi menggunakan software ETAP sebelum pemasangan filter aktif pada SDP memiliki rata-rata sebesar $9,7 \%$ yang masih diatas standar IEEE 519-1992 yang telah ditentukan yaitu sebesar $\leq 5 \%$. Setelah pemasangan filter aktif hight pass pada masing-masing SDP nilai rata-rata $T H D_{1} 1,5 \%$ dan nilai $T H D_{V}$ 0,31\%. Total rugi-rugi daya sebelum pemasangan filter aktif adalah 153.119,8 Watt dan sesudah pemasangan menjadi 1.511,2 Watt. Penurunan nilai filter dipakai $70 \%$ dari kinerja maksimum filter guna mendapatkan filter yang lebih efisien, tetapi masih memenuhi standar THD yang ditentukan dan total rugi-rugi daya diperoleh $11.885,5 \mathrm{~W}$. Adanya pemasangan filter aktif menye-babkan rugi-rugi daya menurun.

\section{Daftar Pustaka}

[1] H. W. B. Surya Santoso and M. F. M. Roger C. Dugan, Electrical Power System Quality. 2003.

[2] Alam Tuara and Laboratorium PBL STT-PLN, "Harmonisa Arus," 08-Mar2015. .

[3] "519-2014 - IEEE Recommended Practice and Requirements for Harmonic Control in Electric Power Systems," IEEE, Jun. 2014.

[4] "Filter Aktif High Pass (HPF)," 19-Jun2012. .

[5] Angga, "Simulasi dan Solusi untuk Meningkatkan Kualitas Daya Listrik di Hotel Best Western Premiere," Tek. Elektro Univ. Udayana, 2014. 